\title{
AÇÃO ANTAGONISTA DE LACTOBACILLUS ACIDOPHILUS FRENTE A ESTIRPES PATOGÊNICAS INOCULADAS EM LEITE FERMENTADO
}

\section{LACTOBACILLUS ACIDOPHILUS ANTAGONISTIC ACTION AGAINST PATHOGENIC STRAINS INOCULATED IN THE FERMENTED MILK}

\author{
Maria Carmela Kasnowski Holanda DUARTE ${ }^{\left[1,{ }^{*}\right]}$; Neila Mello dos Santos CORTEZ $^{[2]}$; Nayara Caldas de \\ MACEDO ${ }^{[3]}$; Marco Antonio Sloboda CORTEZ ${ }^{[1]}$; Robson Maia FRANCO ${ }^{[1]}$ \\ [1] Docente da Universidade Federal Fluminense, Centro de Ciências Médicas, Faculdade de Veterinária. Rua Vital Brasil Filho, n.64 Santa Rosa, \\ 24230-340 - Niterói, RJ - Brasil. masc1971@yahoo.com.br e robsonmf@vm.uff.br \\ [2] Docente da Universidade Federal de Pernambuco, Centro de Tecnologia e Geociências, Faculdade de Engenharia de Alimentos. 4ạ Travessa \\ Professor Artur de Sá. Cidade Universitária 50740521 - Recife, PE - Brasil.neilacortez@yahoo.com.br \\ ${ }^{[3]}$ Discente Curso Engenharia de Alimentos da Universidade Federal de Pernambuco, Centro de Tecnologia e Geociências, Faculdade de Engenharia \\ de Alimentos. 4ạ Travessa Professor Artur de Sá. Cidade Universitária 50740521 - Recife, PE - Brasil. naycaldas@gmail.com
}

*Autor para correspondência: melvetk@gmail.com

\section{INFORMAÇÕES}

Recebido em: 08/09/2015

Aceito em: 10/11/2015

Publicado em: $28 / 03 / 2016$

Document Object Identifier

10.18067/jbfs.v3i1.79

Editor: V. H. G. Sales

jbfs@ifap.edu.br

ID JBFS2015079

Avaliação a cega por pares

Prot. 0792015R01

Prot. $0792015 R 02$

Copyright: (C) 2016

JBFS all rights (BY NC SA)

\section{RESUMO}

Com o presente estudo objetivou-se avaliar a ação antagonista do Lactobacillus acidophilus frente à Escherichia coli, Staphylococcus aureus e Listeria monocytogenes. Foram realizados testes in vitro, utilizando placas de Petri com ágar MRS, e no leite fermentado com Lactobacillus acidophilus, sendo analisadas também as características físico química do produto, durante 35 dias de armazenamento sob refrigeração. Foi observado in vitro formação de halos de inibição, variando de 6 a $18 \mathrm{~mm}$ de diâmetro, frente aos patógenos pelos repiques da cultura lática testada, indicando a possibilidade de produção de ácidos orgânicos, bacteriocinas ou outras substâncias inibidoras de crescimento. No leite fermentado elaborado, durante o armazenamento, o microrganismo probiótico testado foi capaz de inibir E. coli 0157:H7 e L. monocytogenes; e reduzir o ciclo logarítmico de $S$. aureus.

Palavras-chave: Bactérias láticas; Probiótico; inibição; L. monocytogenes; Escherichia coli; S. aureus.

ABSTRACT - With the present study aimed to evaluate the antagonistic action of Lactobacillus acidophilus front of Escherichia coli, Staphylococcus aureus and Listeria monocytogenes. In vitro tests were performed using Petri dishes with MRS agar and the milk fermented with Lactobacillus acidophilus also analyzed the chemistry and physical characteristics of the product during 35 days of storage under refrigeration. It has been observed in vitro formation of inhibition zones, ranging from 6 to $18 \mathrm{~mm}$ diameter, compared to the tested pathogens by lactic culture raises, indicating the possibility of producing organic acids, bacteriocins or other growth-inhibiting substances. In the fermented milk prepared, during storage, the probiotic microorganism tested was able to inhibit the growth of E. coli O157: H7 and L. monocytogenes; and the log cycle reduction of $S$. aureus.

Keywords: Lactic acid bacteria; probiotic; inhibition; L. monocytogenes; E. coli; S. aureus

Financiamento: Os autores reportam que não houve suporte e auxílio financeiro.

Conflito de interesse: Os autores declaram que não há conflito de interesse.

Como referir esse documento (ABNT):

DUARTE, M.C.K.H.; CORTEZ, N.M.S.; CORTEZ, M.A.S.; FRANCO, R.M.; MACEDO, N.C. Ação antagonista de Lactobacillus acidophilus frente a estirpes patogênicas inoculadas em leite fermentado. Journal of Bioenergy and Food Science, Macapá, v.3, n.1, p.1-10, jan./mar., 2016. DOI 10.18067/jbfs.v3i1.79 


\section{INTRODUÇÃO}

O desenvolvimento de produtos alimentícios que promovem a saúde e o bem estar é uma das prioridades da pesquisa na indústria de alimentos e tem favorecido ao consumo de alimentos enriquecidos com componentes fisiologicamente ativos tais como os probióticos. Os alimentos são considerados como um veículo ideal para o fornecimento de probióticos ao trato gastrointestinal humano pelo efeito protetor sobre as cepas probióticas durante a passagem até o seu local de ação, o intestino ${ }^{1}$. No mercado de produtos funcionais a indústria de laticínios é a que apresenta maior disponibilidade de alimentos com probióticos como os iogurtes, leites fermentados e bebidas lácteas fermentadas. ${ }^{2,3}$

Os leites fermentados são definidos como produtos resultantes da fermentação do leite, por fermentos láticos próprios, que devem ser viáveis, ativos e abundantes no produto final durante $o$ prazo de validade. ${ }^{4}$

As culturas probióticas são suplementos microbianos viáveis, o que inclui bactérias láticas e leveduras na forma de células liofilizadas ou de produto fermentado, que aumentam de maneira significativa o valor nutritivo e terapêutico dos alimentos, além de contribuírem para conservação e características sensoriais do produto final ${ }^{5-7}$. Os microrganismos probióticos mais empregados são os dos gêneros Lactobacillus e Bifidobacterium; pertencentes à lista "Generally Recognized as Safe" (GRAS) do "Codex Alimentarius".

Os Lactobacillus acidophilus são bacilos em forma de bastão com as extremidades arredondadas, microearófilos, homofermentadores com temperatura ótima de crescimento a $45 \mathrm{C}^{9}$. São considerados microrganismos com potencial probióticos especialmente por resistirem a baixas tensões superficiais e ao suco gástrico, e pela facilidade em colonizar o intestino grosso. ${ }^{10,11}$

As substâncias antagônicas produzidas por bactérias láticas probióticas correspondem a metabólitos como ácidos orgânicos, peróxido de hidrogênio, radicais livres, diacetileno, acetaldeido, isômeros $D$ de aminoácidos e especialmente bacteriocinas; que constituem proteínas e peptídeos com atividade antibacteriana. ${ }^{12,13}$

Dentre os benefícios ao uso de probióticos, destacam-se o controle das infecções intestinais, o estímulo da motilidade intestinal, a melhor absorção de determinados nutrientes, a melhor utilização da lactose, a redução dos níveis de colesterol, o efeito anticarcinogênico e o estímulo do sistema imunológico. ${ }^{6}$

Diversas estirpes de $E$. coli são comprovadamente patogênicas para o homem e animais, destacando-se a E. coli O157:H7, implicada como agente etiológico da colite hemorrágica e da síndrome urêmica hemolítica. ${ }^{14}$

A Listeria monocytogenes é um microrganismo causador de doença alimentar atípica de alta gravidade, alta mortalidade, longo período de incubação e prevalência particular em indivíduos imunocomprometidos, idosos, crianças, recém-nascidos e gestantes; podendo acometer o sistema nervoso central. ${ }^{15-17} \mathrm{~S}$. aureus está mais relacionado com casos e surtos de intoxicação pela habilidade de sintetizarem enterotoxinas nos alimentos, que estimulam a proliferação nãoespecífica de células $T$, ocasionando quadros de gastroenterites em período de incubação médio de uma a oito horas. ${ }^{18}$

Este trabalho objetivou avaliar in vitro a ação antagonista do Lactobacillus acidophilus e elaborar o leite fermentado para verificar a viabilidade da bactéria lática e o antagonismo frente a estirpes de Escherichia coli 0157:H7, Listeria monocytogenes e Staphylococcus aureus durante o período de armazenamento do produto sob refrigeração.

\section{MATERIAL E MÉTODOS}

Os testes de inibição in vitro foram realizados em duplicata com três repetições, adaptando-se as técnicas de Tagg et al. ${ }^{19}$ e Romeiro ${ }^{20}$, utilizando o L. acidophilus (LA5, Chr. Hansen), E. coli O157:H7 (E 40705-SH1, Public Health Laboratory Science), L. monocytogenes (isolada de amostra de carne bovina) e Staphylococcus aureus (ATCC25923).

O L. acidophilus foi ativado em tubos contendo leite desnatado reconstituído a $10 \%$, esterilizado e posteriormente em caldo MRS (Man Rugosa Sharpe; Acumedia 7543A), incubados ambos a $37^{\circ} \mathrm{C}$ por 48 horas em jarras de anaerobiose. Após ativação, foram confeccionados esfregaços e realizada a coloração de Gram para posterior bacterioscopia e observação das características do cultivo; assim como realizada a prova da catalase. 
A cultura ativada foi semeada, quantidade de $30 \mu \mathrm{L}$, em cinco poços equidistantes em placas contendo ágar MRS e incubadas a $37^{\circ} \mathrm{C}$ em estufa bacteriológica por 48 horas em anaerobiose. Após o período de incubação, as placas foram invertidas e adicionado a cada tampa papel de filtro esterilizado embebido com $1 \mathrm{~mL}$ de clorofórmio por 20 minutos para inativação das culturas. As cepas indicadoras foram previamente ativadas em caldo Brain Heart Infusion (Acumedia 7116A) a 37으 por 24 horas e também observadas quanto às características em microscopia de imersão após confecção de lâminas coradas pelo método de Gram. Inoculou-se 0,1 mL de cada cepa em tubos contendo BHI semi-sólido que foram vertidos sobre a superfície das placas de ágar MRS com as culturas láticas inativadas. As placas foram incubadas a $37^{\circ} \mathrm{C}$ por 72 horas em aerobiose.

Para a elaboração do leite fermentado, foi utilizado leite UHT integral como matéria-prima. O leite UHT foi avaliado quanto a qualidade bacteriológica através da Contagem de Bactérias Heterotróficas Aeróbias Mesófilas, Pesquisa de Salmonella spp., Pesquisa de $S$. aureus e Pesquisa de $E$. coli empregando-se o teste rápido $\mathrm{Rida}^{\circledR}$, seguindo a metodologia do fabricante. Realizou-se também, em triplicata, a pesquisa de resíduos de antimicrobianos com o teste Eclipse (CAP-LAB), mensurou-se o $\mathrm{pH}$ e a acidez ${ }^{21}$ e a crioscopia com auxílio de crioscópio eletrônico (MC5400).

A cultura láctica utilizada foi o Lactobacillus acidophilus adicionado diretamente aos 25L de leite no tanque misturador, na proporção de $25 \mathrm{~g}$ de cultura para $250 \mathrm{~L}$ de leite. Posteriormente, a mistura foi envasada em 100 garrafas plásticas tipo "pet" (Embali $\left.{ }^{\oplus}\right)$ de $250 \mathrm{~mL}$, previamente esterilizadas em autoclave a $121^{\circ} \mathrm{C} / 15 \mathrm{~min}$, e incubada em estufa à temperatura de $45^{\circ} \mathrm{C}$ para promover $\mathrm{o}$ processo de fermentação. $\mathrm{O}$ desenvolvimento da acidez foi acompanhada em intervalos de 01 hora pelo método de Dornic e $\mathrm{pH}^{21}$. Após alcançar a acidez desejada, definida como $\mathrm{pH}$ de 4,5, as garrafas foram retiradas da estufa e separadas em grupos experimentais: amostras controle, contendo apenas o inóculo da cultura lática probiótica; e amostras indicadoras inoculadas com as estirpes patogênicas.

As estirpes patogênicas utilizadas como culturas indicadoras foram às testadas previamente in vitro: E. coli O157:H7, S. aureus e L. monocytogenes. Os microrganismos foram previamente semeados para ativação em ágar
Nutriente e incubados em estufa bacteriológica a $37^{\circ} \mathrm{C}$ por 24 horas. Todas as culturas antes de serem inoculadas foram avaliadas quanto à morfologia em microscópio de objetiva de imersão, após confecção de esfregaços em lâminas e coloração pelo método de Gram. As culturas indicadoras foram transferidas para solução salina esterilizada com auxílio de alça de platina até que a concentração alcançasse a escala 1,0 de MacFarland, que equivale $3,0 \times 10^{8}$ bactérias $/ \mathrm{mL}$ $(8,4 \log$ bacts $/ \mathrm{mL})$. Inoculou-se a suspensão de um mililitro de cada estirpe, em $250 \mathrm{~mL}$ de leite fermentado, totalizando 25 garrafas do produto para cada microrganismo patogênico.

A amostra controle foi analisada em triplicata quanto ao teor de gordura pelo método de Gerber e ao teor de proteína pelo método de Kjeldahll, de acordo com metodologia preconizada na legislação ${ }^{21}$.

As amostras controle e indicadoras foram armazenadas em refrigeração a $5^{\circ} \mathrm{C}$ durante um período de 35 dias para realização das análises bacteriológicas e avaliação da acidez nos dias 0,1 , $2,3,4,5,6,7,8,9,10,14,21,23,25,28,30$ e 35 após produção.

A contagem de L. acidophilus foi realizada em ágar Man Rugosa Sharpe (Acumedia 7543A) por semeadura em profundidade. As placas foram incubadas em jarra de anaerobiose (Anaerobac) em estufa bacteriológica a $37^{\circ} \mathrm{C}$ por 72 horas. Após incubação selecionaram-se as placas que apresentaram UFC brancas e leitosas, circulares e com bordas perfeitas. Foram confeccionados esfregaços em lâminas de vidro e corados pelo método de Gram para observação em microscopia das características morfotintoriais das UFC, assim como realizada a prova da catalase com adição às placas de peróxido de hidrogênio $10 \%$. Os cultivos apresentaram prova da catalase negativa e presença de bastonetes Gram positivos, sendo confirmados como Lactobacillus acidophilus.

A contagem de $E$. coli $\mathrm{O} 157$ foi realizada em ágar Mac Conckey Sorbitol (Acumedia 7320A) e a enumeração de Listeria moncytogenes em Listeria Agar Selectivo Oxford (Merck 7004), após semeadura em profundidade de $1 \mathrm{~mL}$ de cada amostra. A contagem de $S$. aureus foi realizada por espalhamento em superfície de $0,1 \mathrm{~mL}$ em ágar Baird Parker (Merck 5406). As placas semeadas foram incubadas em aerobiose em estufa bacteriológica a $37^{\circ} \mathrm{C}$ por 48 horas. $^{22}$ 
Todas as análises foram realizadas em duplicata e os resultados correspondem a média das contagens. Os dados bacteriológicos foram convertidos para log UFC/mL e avaliados estatisticamente através da análise de regressão.

\section{RESULTADOS E DISCUSSÃO}

Nos resultados obtidos na presente pesquisa, dos 30 repiques de $L$. acidophilus testados frente a $E$. coli, em $26,6 \%$ (oito) foi observada atividade antagonista confirmada pela produção de halos de inibição variando de 6 a 18 $\mathrm{mm}$ de diâmetro. Dos 30 cultivos de L. acidophilus avaliados com culturas de L. monocytogenes, 13,3\% (quatro) apresentaram zona de inibição de $12 \mathrm{~mm}$; e com $S$. aureus $16,6 \%$ (cinco) formaram halos de $12 \mathrm{~mm}$ e 3,3\% (um) de $18 \mathrm{~mm}$ de diâmetro. Pesquisas similares foram encontradas na literatura consultada, como Alexandre et al. ${ }^{12}$ que analisaram a atividade antimicrobiana de bactérias láticas isoladas de queijo minas artesanal e observaram que das 192 cepas isoladas $25 \%$ foram capazes de inibir o crescimento in vitro de microrganismos indicadores, dentre os quais $S$. aureus e $L$. monocytogenes. Porém, diferente dos $46,5 \%$ repiques formadores de halo de inibição frente a $E$. coli analisados neste estudo, os autores observaram que nenhuma das cepas isoladas foi capaz de inibir este microrganismo.

Os resultados deste experimento estão em concordância com os de Neto et al. ${ }^{23}$, demonstraram a ação antagonista de bactérias ácido láticas e identificaram que Lactobacillus spp. foi o que mais proporcionou inibição de microrganismos patogênicos testados, como $S$. aureus, L. monocytogenes e E. coli. Por sua vez, Kayser $^{24}$ demonstrou, através do teste de inibição direta por bactérias láticas, porcentagens superiores às encontradas neste estudo, correspondentes a $95,23 \%$ de inibição para $S$. aureus e $97,61 \%$ de inibição para L. monocytogenes frente às estirpes testadas.

$\mathrm{Na}$ atual pesquisa os diâmetros dos halos de inibição mensurados variaram de 6 a $18 \mathrm{~mm}$, corroborando com os valores relatados na literatura por Chioda et al. ${ }^{11}$ que observaram a inibição de E. coli BIA26 por todas as cepas de Lactobacillus acidophilus testadas, pela presença de halos variando de 9,0 a 15,0 mm de diâmetro. Por sua vez, Pereira e Goméz ${ }^{25}$ avaliaram a ação de Lactobacillus acidophilus sobre E. coli e $S$. aureus e identificaram a produção de uma substância extracelular e difusível ocasionando o aparecimento de halos de inibição de 14,75 e 15,0 $\mathrm{mm}$ de diâmetro respectivamente. Também Poppi et al. $^{26}$ analisaram a atividade antagonista de diferentes espécies de Lactobacillus sobre $L$. monocytogenes em meio de cultura adicionado ou não de bicarbonato de sódio; e observaram formação de áreas de inibição variando de 6,0 a $11,5 \mathrm{~mm}$ para o meio neutralizado e de 9,0 a 13,5 $\mathrm{mm}$ de diâmetro no meio sem neutralização. Costa et al. ${ }^{27}$ observaram halos de inibição variando entre 23,0 e 29,0 mm formados por ação de Lactobacillus acidophilus nos testes de difusão em ágar frente a S. aureus e E. coli.

No presente trabalho não foi avaliada a natureza das substâncias antagonistas produzidas pelas culturas láticas, porém as atividades inibitórias verificadas foram justificadas, em literatura específica, pela difusão de substâncias inibidoras no ágar, como ácido lático, que impediram o crescimento por interferirem no metabolismo das culturas patogênicas indicadoras, conforme relatos de Pereira e Gómez. ${ }^{25}$

A atividade antimicrobiana direta produzida pela microbiota estudada nesta pesquisa pode ser devida a vários fatores como: a produção de ácidos orgânicos, de peróxido de hidrogênio, de diacetil, de dióxido de carbono, de acetaldeído e de bacteriocinas, entre outros.

Em relação à avaliação da matéria prima utilizada para a elaboração do leite fermentado, os resultados obtidos atenderam aos padrões determinados no regulamento, confirmando a qualidade desejável da matéria prima ${ }^{28}$. A fermentação do produto teve duração de 24 horas, quando o leite fermentado atingiu valores de $\mathrm{pH}$ e acidez titulável correspondentes a 4,57 e a 0,8 gramas de ácido lático $/ 100 \mathrm{~mL}$ respectivamente, em conformidade com o especificado pela legislação ${ }^{4}$. O processo fermentativo longo é explicado pelo lento crescimento do L. acidophilus, que requer grande quantidade de nutrientes, devendo ser utilizado maior concentração de inóculo (2-5\%). ${ }^{10}$

Após o período de fermentação e estocagem, os teores de proteína e gordura do produto final foram respectivamente $3,4 \%$ e $3,2 \%$, correspondendo ao padrão de identidade e qualidade dos produtos no regulamento vigente. ${ }^{4}$ 
No decorrer do período de 35 dias de armazenamento, sob refrigeração a $5^{\circ} \mathrm{C}$, houve redução do $\mathrm{pH}$ com consequente aumento da acidez do produto. $\mathrm{O} \mathrm{pH}$ final do produto foi de 4,34 e a acidez titulável de 1,01 gramas de ácido lático/100mL de amostra, em conformidade com os valores de acidez de no mínimo $0,6 \mathrm{~g}$ de ácido láctico/100g do produto e no máximo $2,0 \mathrm{~g}$ de ácido láctico/100g do produto preconizados pela legislação. ${ }^{4}$

A alteração observada com relação ao pH e acidez do leite fermentado, provavelmente, foi devido ao metabolismo do L. acidophilus, que a partir da fermentação da lactose ocasionou a formação de ácido lático; visto que é considerado um microrganismo homofermentador conforme descrição de Viegas. ${ }^{9}$ Essa característica do leite fermentado acidófilo é um fator que favorece a inibição do crescimento de microrganismos indesejáveis, como as bactérias deteriorantes e patogênicas. A variação, de acidez e de $\mathrm{pH}$, observada durante o período de armazenamento do leite fermentado elaborado neste experimento, não foi prejudicial à viabilidade do L. acidophilus que foi mantido acima do limite mínimo aceitável.

A relação entre contagens de células bacterianas $(Y)$ e tempo de armazenamento $(X)$ do leite fermentado acidófilo foi estudada através da análise de regressão sugerindo a formação de uma reta no gráfico, equações lineares representadas na Tabela 1.

Tabela 1. Equações de Regressão linear.

Table 1. Linear regression equations.

\begin{tabular}{cccc} 
AMOSTRAS & $\begin{array}{c}\text { MODELODE } \\
\text { EQUAÇÃO }\end{array}$ & $R^{2}$ & $\mathrm{Pi}>\mathrm{F}$ \\
\hline $\mathrm{C}$ & $\mathrm{Y}=13,43-0,13 \mathrm{X}$ & 0,81 & 0,0001 \\
11 & $\mathrm{Y}=9,25-0,04 \mathrm{X}$ & 0,91 & 0,0001 \\
12 & $\mathrm{Y}=7,92-0,02 \mathrm{X}$ & 0,79 & 0,0001 \\
13 & $\mathrm{Y}=9,13-0,04 \mathrm{X}$ & 0,89 & 0,0001
\end{tabular}

$\mathrm{C}=$ amostra controle (L. acidophilus); $\mathrm{I} 1=$ Amostra Indicadora 1 (E. coli $0157: \mathrm{H7}) ; 12=$ Amostra Indicadora 2 (S. aureus); $13=$ Amostra Indicadora 3 (L. monocytogenes). $Y=$ contagem de células bacterianas; $X=$ tempo em dias de armazenamento do iogurte.

$C=$ Control sample (L. acidophilus); $11=$ indicator sample 1 (E. coli O157:H7); $12=$ indicator sample 2 (S. aureus); $13=$ indicator sample 3 (L. monocytogenes). $Y=$ bacterial cell count; $X=$ time in days the storage of yoghurt.
A população inicial de $L$. acidophilus foi de $13,4 \log$ UFC/g do produto. Durante o período de 35 dias de estocagem ocorreu uma leve redução na concentração bacteriana para 11,6 log UFC/g, representada no gráfico da Figura 1 , o que não influiu na característica final do produto, uma vez que as contagens foram superiores ao valor preconizado na legislação correspondente a $10^{7}$ UFC/g $(7,0$ log UFC/g) de alimento 4 .

Os resultados encontrados são indicativos da manutenção da viabilidade da cultura probiótica utilizada na elaboração do leite fermentado durante todo o prazo de estocagem, atendendo a propriedade funcional aprovada pela ANVISA, que especifica como quantidade mínima viável para os probióticos a faixa de $10^{8}$ a $10^{9}$ UFC $(8,0-9,0$ log UFC) na recomendação diária do produto pronto para o consumo conforme indicação do fabricante ${ }^{29}$. A composição dos derivados lácteos em geral é propícia a incorporação de probióticos, como demonstrado por Lima et al. $^{3}$ em leite de ovelha fermentado por Kefir e Rolim et al. ${ }^{1}$ ao avaliarem a viabilidade de Lactobacillus rhamnosus em queijo coalho frente a condições simuladas do trato gastrointestinal.

Figura 1. Resultado das contagens bacteriológicas, em $\mathrm{UFC} / \mathrm{mL}$, nas amostras controle ( $\mathrm{C}=\mathrm{L}$. acidophilus); e nas amostras indicadoras de E. coli O157:H7 (I1); S. aureus (I2); e L. monocytogenes (I3), do leite fermentado armazenado a $5^{\circ} \mathrm{C}$ por 35 dias.

Figure 1. Results of bacteriological counts in CFU / $\mathrm{mL}$ in the control samples ( $C=L$. acidophilus); and the indicator strains of E. coli 0157:H7 (I1); S. aureus (12); and L. monocytogenes (I3) of the fermented milk, stored at $5^{\circ} \mathrm{C}$ for 35 days.

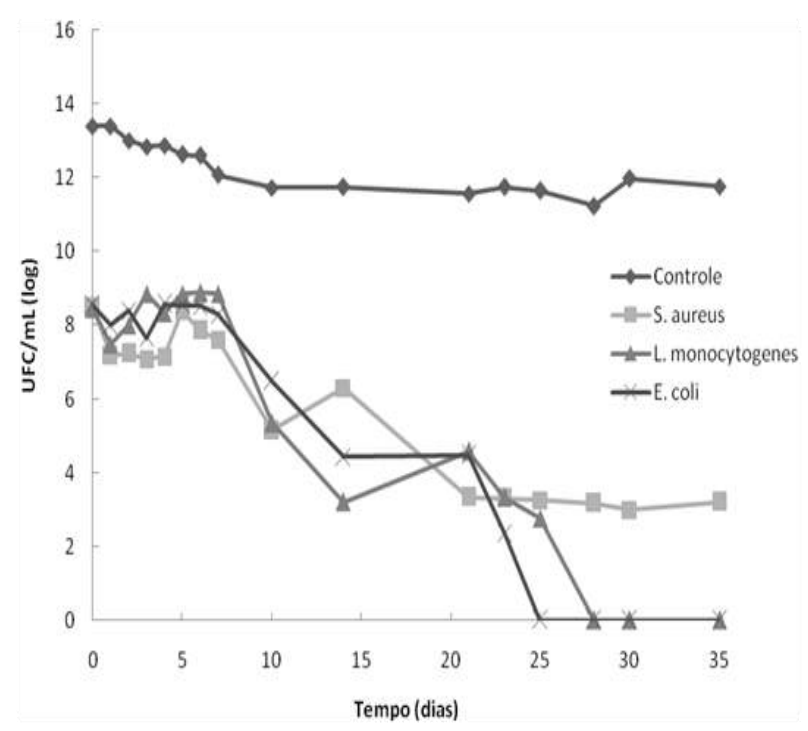

Fonte: Autores.

Font: Authors 
De maneira similar, a viabilidade de $L$. acidophilus durante a estocagem foi observada por Zacarchenco e Massaguer-Roig ${ }^{30}$ que obtiveram contagem bacteriana de $2,1 \times 10^{8} \mathrm{UFC} / \mathrm{mL}(8,3 \mathrm{log})$, Thamer e Penna ${ }^{31}$ determinaram $1,15 \times 10^{8}(8,0$ log) a $2,55 \times 10^{12}(12,4 \mathrm{log}) \mathrm{UFC} / \mathrm{mL}$ e Ramos et al. ${ }^{2}$ $11,6 \log \mathrm{UFC} / \mathrm{mL}$, reforçando que os produtos lácteos avaliados foram potencialmente favoráveis à promoção dos efeitos terapêuticos do probiótico. Entretanto, Barreto et al. ${ }^{32}$ ao avaliar os leites fermentados com $L$. acidophilus comercializados no Brasil verificaram contagens variando de 6,66 a 8,60 log UFC/g de produto. Cunha et al. ${ }^{33}$ encontraram valores para contagem de bactérias probióticas inferiores aos obtidos na presente pesquisa, correspondentes de $1,7 \times 10^{6}(6,2 \mathrm{log})$ a $9,8 \times 10^{6}(6,9 \mathrm{log}) \quad \mathrm{UFC} / \mathrm{g}$ durante 28 dias de estocagem e concluíram que a variação foi dependente da matéria prima utilizada na elaboração do leite fermentado e não do tempo de armazenamento a $5^{\circ} \mathrm{C}$. Por sua vez, Gonçalves e Eberle $^{34}$ deduziram que a acidificação do produto final, os ácidos produzidos durante o armazenamento, o nível de oxigênio no produto e a permeação do oxigênio através da embalagem podem reduzir a viabilidade das culturas probióticas.

As contagens iniciais das amostras indicadoras (E. coli 0157:H7, S. aureus e $L$. monocytogenes) foram $8,4 \log \mathrm{UFC} / \mathrm{mL}$, e decresceram muito lentamente durante o período de armazenamento. Analisando a Figura 1, observa-se que E. coli (I1) não foi mais detectável no produto a partir do vigésimo quinto dia de estocagem, quando ocorreu morte celular, provavelmente por exclusão competitiva por nutrientes ou pela ação de ácidos orgânicos como descrito por Calderon et al. ${ }^{35}$, Alves ${ }^{36}$, Costa et al. ${ }^{37}$ e Marques et al. ${ }^{38}$.

A L. monocytogenes (I3) manteve viabilidade até o vigésimo oitavo dia, a partir do qual não foi mais detectada, indicando ter ocorrido lise celular, provavelmente pelos mesmos fatores supracitados. Já $S$. aureus (12) foi reduzido em cinco ciclos logarítmicos para 3,2 log UFC/mL, entretanto manteve-se viável durante 0 período de armazenamento.

Similarmente, Barrantes et al. ${ }^{39}$ avaliaram a atividade antagonista de culturas probióticas, $L$. acidophillus e L. casei, adicionadas em iogurtes inoculados com L. monocytogenes e E. coli. Os pesquisadores também observaram a eficiência dos probióticos que permaneceram com contagens de $10^{8} \mathrm{UFC} / \mathrm{g}(8,0 \mathrm{log} \mathrm{UFC} / \mathrm{g})$ e proporcionaram a inibição de L. monocytogenes após o oitavo dia de armazenamento e $E$. coli no décimo sexto dia.

Apesar da similaridade dos resultados desta pesquisa com os dados obtidos em literatura, Victal e Knight $^{40}$ observaram a inibição de $E$. coli pelo microrganismo probiótico em menor período de tempo; assim como Calderon et al. ${ }^{35}$ que verificaram a ação inibitória do $L$. acidophillus adicionado a iogurte sobre $L$. monocytogenes a partir do décimo segundo dia e $E$. coli após o oitavo dia de armazenamento.

Entretanto o resultado, referente à manutenção da viabilidade das estirpes de $S$. aureus neste trabalho, difere do achado por Calderon et al. $^{35}$ que registraram o desaparecimento do microrganismo patogênico a partir do décimo segundo dia de estocagem sob refrigeração. Souza ${ }^{41}$ estudou a evolução das bactérias Staphylococcus spp. e coliformes totais em queijo minas frescal adicionado de $L$. acidophilus e também verificou que ocorreu inibição dos microrganismos contaminantes pela ação da cultura probiótica; diferente do resultado desta pesquisa na qual não foi observada a inibição de S. aureus.

A atividade antagonista do L. acidophilus também foi demonstrada por outros pesquisadores que trabalharam com elaboração de queijos, no entanto, igualmente aos dados do presente experimento, Chioda et. al. ${ }^{42}$ averiguaram total inibição de L. monocytogenes, mas em 10 dias de armazenamento. Por sua vez, Alves ${ }^{36}$ e Marques et al. $^{38}$ verificaram apenas a redução de 3,0 e 4,5 ciclos logarítmicos, respectivamente, no crescimento de $E$. coli ao longo de 30 dias de armazenamento de queijo minas frescal e queijo minas padrão, resultado diferente do encontrado neste trabalho onde houve inibição total do microrganismo no vigésimo quinto dia de armazenamento.

Além disso, determinados fatores podem influenciar na eficiência da ação inibitória dos microrganismos probióticos como o estágio de contaminação, a dose do inóculo contaminante, o tipo de cepa, a resistência a ácido, a quantidade e o tipo de bactéria ácido lática utilizada; associados ainda ao conjunto de fatores intrínsecos e extrínsecos ao alimento, que constituem os obstáculos tecnológicos ao crescimento 
microbiano ${ }^{14,43-45}$. Os fatores pontuados, possivelmente constituem a causa da manutenção da população de $S$. aureus no leite fermentado elaborado neste experimento e armazenado sob refrigeração.

\section{CONCLUSÃO}

A cultura de $L$. acidophilus foi capaz de inibir o crescimento de estirpes patogênicas, entretanto cepas da mesma espécie podem apresentar variações na formação de halos pela diferente quantidade e variação de substâncias antimicrobianas produzidas, conferindo especificidade. A atividade antagonista observada sobre estirpes patogênicas pode constituir uma das vantagens do uso de culturas láticas e probióticas na produção de alimentos.

O L. acidophilus utilizado na elaboração do leite fermentado manteve-se viável durante o período de armazenamento, apresentou ação antagonista total no desenvolvimento de estirpes de $E$. coli e de $L$. monocytogenes, e inibiu parcialmente $S$. aureus; conferindo desta forma características probióticas ao produto final. Entretanto para que a efetividade da cultura probiótica seja garantida, a interação entre determinados fatores intrínsecos e extrínsecos ao alimento, que influenciam no crescimento e metabolismo microbiano, deve ser considerada.

\section{CONTRIBUIÇÃO DOS AUTORES}

1 - Planejamento, orientação (microbiologia de alimentos), delineamento experimental e revisão final do trabalho/artigo.

\section{Robson Maia Franco 9}

2 - Condução e avaliação do experimento, orientação (processamento leite fermentado), análise estatística e revisão final do trabalho/artigo

\section{Marco Antonio Sloboda Cortez}

3 - Elaboração do leite fermentado, realização do experimento, análises microbiológicas e físicoquímicas, redação do trabalho e artigo

\section{Maria Carmela Kasnowski Holanda Duarte 9}

4 - Elaboração do leite fermentado, revisão final e formatação do artigo.

Neila Mello dos Santos Cortez

5 - Abstract, revisão final e formatação do artigo.

Nayara Caldas de Macedo

\section{REFERÊNCIAS}

[1]. ROLIM, F.R.L.; SANTOS, K.M.O.; BARCELOS, S.C.; RIBEIRO, T.H.; CONCEIÇÃO, M.L.;OLIVEIRA, M. E. G.; MAGNANI, M.;QUEIROGA, R.C.R.E. Avaliação in Vitro do Potencial Probiótico de Queijo Coalho Caprino Adicionado de Lactobacillus rhamnosus. Blucher Food Science Proceedings. São Paulo: Blucher. número 1, volume 1. nov. 2014.

[2]. RAMOS, A.C.S.M.; STAMFORD, T.L.M.; MACHADO, E.C.L.M.; LIMA F.R.B.; GARCIA, E.F.; ANDRADE, S.A.C.; SILVA, G.M.S. Elaboração de Bebidas Lácteas Fermentadas: Aceitabilidade e Viabilidade de Culturas Probióticas. Ciências Agrárias. Londrina. v.34, n.6, p.2817-2828, 2013.

[3]. LIMA, M.S.F.; SILVA, R. A.; SILVA, M.F.; PORTO, A.L.F.; CAVALCANTI, M.T.H. Características Microbiológicas e Antioxidantes de um Novo Alimento Funcional Probiótico: Leite de Ovelha Fermentado por Kefir. XX congresso Brasileiro de Engenharia Química. COBEQ: Florianópolis/SC. out.2014. Disponível em: <http://www.proceedings.blucher.com.br/>. Acesso em 25 de out 2015 .

[4]. BRASIL. Ministério da Agricultura, Pecuária e Abastecimento. Instrução Normativa no46, de 23 de outubro de 2007. Padrões de Identidade e Qualidade de Leites Fermentados. Diário Oficial da União, Brasília, DF, 24 de out. 2007. Seção 1, pt. 5.

[5]. BOOBIER, W.J.; BAKER, J.S.; DAVIES, B. Development of a healthy biscuit: an alternative approach to biscuit manufacture. Nutrition Journal, London, v.5, n.7, p. 1-7. 2006.

[6]. FRANCO, R.M.; OLIVEIRA, L.A.T.; CARVALHO, J.C.A.P. Probióticos - Revisão. Higiene Alimentar. São Paulo, v.20, n.142, p.22-33, jul. 2006.

[7]. REIS, A.R.N.; GOULART, P.F.P.G; SILVEIRA, I.A. Elaboração de Bebida Simbiótica e Avaliação de sua Qualidade Sensorial e Microbiológica. Higiene Alimentar. São Paulo, v.21, n.151, p. 3136, maio. 2007.

[8]. KEMPKA, A.P; KRUGER, R.L.; VALDUGA, E.; DI LUCCIO, M.; TREICHER, H.; CANSIAN, R., 
OLIVEIRA, D. Formulação de bebida láctea fermentada sabor pêssego utilizando substratos alternativos e cultura probiótica. Ciência e Tecnologia de Alimentos. Campinas: Sociedade Brasileira de Ciência e Tecnologia de Alimentos, v.28, n.0, p. 170-177, dez. 2008.

[9]. VIEGAS, R.P. Leites Fermentados Probióticos Produzidos a Partir de Bactérias Ácido Lácticas e Adicionados de Concentrado Protéico de Soro Lácteo: Características Físico-Químicas, Microbiológicas e Sensoriais. Belo Horizonte, 2008, 70 f. Dissertação (Mestrado em Ciência Animal) - Escola de Veterinária da Universidade Federal de Minas Gerais, UFMG. Belo Horizonte, 2008.

[10]. FERREIRA, C.L.L.F. Produtos Lácteos Fermentados: Aspectos Bioquímicos e Tecnológicos. 2 ed. UFV. Viçosa. 2001. 112p.

[11]. CHIODA, T.P.; SCHOCKEN-ITURRINO, R.P.; GARCIA, G.R.; PIGATTO, C.P.; RIBEIRO, C.A.M.; RAGAZZANI, A.V.F. Inibição do crescimento de Escherichia coli isolada de Queijo "Minas Frescal" por Lactobacillus acidophilus. Ciência Rural, v.37, n.2, p.583-585, mar-abr. 2007.

[12]. ALEXANDRE, D.P.; SILVA, M.R.; SOUZA, M.R.; SANTOS, W.L.M. Atividade antimicrobiana de bactérias lácticas isoladas de queijo-de-minas artesanal do Serro (MG) frente a microrganismos indicadores. Arquivo Brasileiro de Medicina Veterinária e Zootecnia. Belo Horizonte, v. 54, n.4, jul/ago. 2002.

[13]. GUERRA, M.M; BERNARDO, F.M.A. Influência da microflora de cura na ocorrência de Listeria spp. em queijos tradicionais. Revista Portuguesa de Ciências Veterinária. Lisboa, v.100, n.555-556, p.185-188. 2005.

[14]. FRANCO, B.G.M.; LANDGRAF, M. Microbiologia dos Alimentos. São Paulo: Atheneu. 2005. 182p.

[15]. MCLAUCHILIN, J.; MITCELL, R.T.; SMERDON, W.J.; JEWELL, K. Listeria monocytogenes and listeriosis: a review of hazard characterization for use in microbiological risk assessment of foods. International Journal of Food Microbiology. Elsevier, v. 92, n. 1, p. 15-33, abr. 2004.

[16]. MENA, C.; ALMEIDA, G.; CARNEIRO, L.; TEIXEIRA, P.; HOGG, T.; GIBBS, P.A. Incidence of Listeria monocytogenes in different foods products commercialized in Portugal. Food Microbiology. Elsevier, v. 21, n. 2, p. 213-216, abr. 2004

[17]. JAY, J.M. Microbiologia de Alimentos. 6 ed, Porto Alegre: Artmed, 2005. 711p.
[18]. HAJDENWURCEL, J.R. Atlas de Microbiologia de Alimentos. São Paulo: Fonte Comunicações e Editora, 2004, v.1. 66p.

[19]. TAGG, J.R; DAJANI, A.S; WANNAMAKER, L.M. Bacteriocin of Gram-positive bacteria. Bacteriological Review. American Society Microbiology, v.40, n.3, p. 722-756, set. 1976.

[20]. ROMEIRO, R.S. Constatação da Produção de Bacteriocinas por Isolamentos de Bactérias Fitopatogênicas. Universidade Federal de Viçosa. Departamento de Fitopatologia. MG. Brasil. 2005. Disponível em:

<www.ufv.br/dfp/bac/uni15.pdf $>$. Acesso em 20 de abril de 2015.

[21]. BRASIL. Ministério da Agricultura, Pecuária e Abastecimento. Instrução Normativa n 68, de 12 de dezembro de 2006. Métodos Analíticos Oficiais Físico-Químicos para Controle de Leite e Produtos Lácteos. Diário Oficial da União, Brasília, DF, p. 8, 12 de dez. 2006. Seção 1.

[22]. DOWNES, F.P.; ITO, K. Compendium of methods for microbiological examination of foods. 4 ed. Washington: APHA, 2001. 676p.

[23]. NETO, L.G.G.; SOUZA, M.R.; NUNES, A.C.; NICOLI, J.R.; SANTOS, W.L.M. Atividade antimicrobiana de bactérias ácido-lácticas isoladas de queijos de coalho artesanal e industrial frente a microrganismos indicadores. Arquivo Brasileiro de Medicina Veterinária e Zootecnia. v.57, supl. 2, p.245-250, 2005.

[24]. KAYSER, V.L. Atividade Antimicrobiana de Bactérias Lácticas Isoladas de Embutidos Curados Frente à $S$. aureus, L. monocytogenes e Salmonella spp. Frederico Westphalen, 2007, 37f. Monografia (Conclusão de Curso Ciências Biológicas) - Universidade Regional Integrada do Alto Uruguai e das Missões - Campus de Frederico Westphalen. Jul 2007.

[25]. PEREIRA, V.G.; GOMÉZ, R.J.H. Atividade antimicrobiana de Lactobacillus acidophilus, contra microrganismos patogênicos veiculados por alimentos. Semina: Ciências Agrárias. Londrina, v.28, n. 2, p. 229-240, abr./jun. 2007.

[26]. POPPI, L.B.; MANCILHA, I.M.; FERREIRA, A.J.P.; LEAL, D.D.M. Avaliação do efeito antagônico de espécies de Lactobacillus sobre Listeria monocytogenes in vitro. Brazilian Journal of Food Technology. Campinas: ITAL, v.11, n.2, p.113-119, abr/jun, 2008.

[27]. COSTA, G.N.; SUGUIMOTO, H.H.; MIGLIORANZA, L.H.S.; GOMEZ, R.J.H.C. Atividade Antimicrobiana de Lactobacillus e 
Bifidobacterium frente a microrganismos patogênicos "in vitro". Ciências Agrárias. Londrina, v. 33, n. 5, p. 1839-1846, set./out. 2012.

[28]. BRASIL. Ministério da Agricultura, Pecuária e Abastecimento. Portaria no 370, de 04 de setembro de 1997. Diário Oficial da União. Regulamento Técnico de Identidade e Qualidade do Leite UHT (UAT). Brasília. 1997.

[29]. BRASIL. Ministério da Saúde. Agência Nacional de Vigilância Sanitária. Comissões e Grupos de Trabalho. Comissão Tecnocientífica de Assessoramento em Alimentos Funcionais e Novos Alimentos. Alimentos com alegações de propriedades funcionais e ou de saúde, novos alimentos/ingredientes, substâncias bioativas e probiótios. IX - Lista de alegações de propriedade funcional aprovadas. 11/01/2015. Disponível em:

$<$ http://www.anvisa.gov.br/alimentos/comissoes/tec no lista alega.htm>. Acesso em 20 de ago de 2015.

[30]. ZACARCHENCO, P.B.; MASSAGUER-ROIG, S. Avaliação sensorial, microbiológica e de pósacidificação durante a vida-de-prateleira de leites fermentados contendo Streptococcus thermophilus, Bifidobacterium longum e Lactobacillus acidophilus. Ciência e Tecnologia de Alimentos. Campinas, v.24, n.4, oct/dec. 2004.

[31]. THAMER, K.G.; PENNA, A.L.B. Efeito do teor de soro, açúcar e defrutooligossacarídeos sobre a população de bactérias lácticas probióticas em bebidas fermentadas. Revista Brasileira de Ciências Farmacêuticas. Brazilian Journal of Pharmaceutical Sciences. São Paulo, v.41, n.03, p.393-400, jul./set., 2005.

[32]. BARRETO, G.P.M.; SILVA, N.; SILVA, E.N.; BOTELHO, L.; YIM, D.K.; ALMEIDA, C.G.; SABA, G.L. Quantificação de Lactobacillus acidophilus, Bifidobactérias e Bactérias Totais em Produtos Probióticos Comercializados no Brasil. Brazilian Journal of Food Technology, Campinas, v.6, n.1, p.119-126, jan./jun. 2003.

[33]. CUNHA, T.M.; ILHA, E.C.; AMBONI, R.D.M.C.; BARRETO, P.L.M.; CASTRO, F.P.; PRUDÊNCIO, E.S. A influência do uso de soro de queijo e bactérias probióticas nas propriedades de bebidas lácteas fermentadas. Brazilian Journal of Food Technology. Campinas, v. 12, n. 1, p. 23-33, jan./mar. 2009.

[34]. GONÇALVES, A.A.; EBERLE, I.R. Frozen yogurt with probiotic bacteria. Alimentos e Nutrição -
Brazilian Journal of Food and Nutrition. Araraquara, v.19, n.3, p. 291-297, jul./set. 2008.

[35]. CALDERON, O; PADILLA, C.; CHAVES, C.; VILLALOBOS, L.; ARIAS, M.L. Evaluación del efecto del cultivo probiótico Lactobacillus rhamnosus adicionado a yogurt natural y con probióticos comerciales sobre poblaciones de Staphylococcus aureus, Escherichia coli 0157:H7, Listeria monocytogenes y Salmonella enteritidis, Archivos Latinoamericanos de Nutrición. Caracas, v.57, n.1, mar. 2007.

[36]. ALVES, C.C.C. Comportamento da Escherichia coli em queijo Minas Frescal elaborado com utilização de Lactobacillus acidophylus e de acidificação direta com ácido láctico. Niterói, 2010, 80 f. Dissertação (Mestrado em Higiene Veterinária e Processamento Tecnológico de POA) - Faculdade de Medicina Veterinária, Universidade Federal Fluminense. Niterói, 2010.

[37]. COSTA, G.N.; SUGUIMOTO, H.H.; MIGLIORANZA, L.H.S.; GOMEZ, R.J.H.C. Atividade Antimicrobiana de Lactobacillus e Bifidobacterium frente a microrganismos patogênicos "in vitro". Ciências Agrárias. Londrina, v. 33, n. 5, p. 1839-1846, set./out. 2012.

[38]. MARQUES, K.A.; MARTINS, A.D.O.; SOARES, B.G.; MARTINS, M.L.; MARTINS, J.M.; BITTRNCOURT, F. Inibição de microrganismos bioindicadores em queijo Minas Padrão com culturas lácticas adicionadas. Tecnologia \& Ciência Agropecuária. João Pessoa, v.7, n.2, p.6974, jun. 2013.

[39]. BARRANTES, X.; RAILEY, D.; ARIAS, M.L.; CHAVES, C. Evaluación del efecto de cultivos probióticos adicionados a yogurt comercial, sobre poblaciones conocidas de Listeria monocytogenes y Escherichia coli 0157:H7. Archivos Latinoamericanos de Nutrición, Caracas, v.54, n.3, sept, 2004.

[40]. VICTAL, C.L.; KNIGHT, I.C.S. Avaliação da Vida Útil de Bebidas Lácteas Fermentadas Obtidas por Fermentação Continua e Descontinuada. Disponível em:

$<$ http://www.unimep.br/phpg/mostraacademica/ana is/4mostra/pdfs/108.pdf >. Acesso em $15 \mathrm{de}$ fev. 2015.

[41]. SOUZA, C.H.B. Influência de uma Cultura "Starter" Termofílica sobre a viabilidade de Lactobacillus acidophylus e as características de queijo minas frescal probiótico. São Paulo, 2006, 110 f. Dissertação (Mestrado em Tecnologia Bioquímico Farmacêutica) - Faculdade de 
Ciências Farmacêuticas, Universidade de São Paulo. São Paulo, 2006.

[42]. CHIODA, T.P.; SCHOCKEN-ITURRINO, R.P.; GARCIA, G.R.; PIGATTO, C.P.; RIBEIRO, C.A.M.; RAGAZZANI, A.V.F. Inibição do crescimento de Listeria monocytogenes em queijo Minas Frescal elaborado com cultura de Lactobacillus acidophilus. Revista Portuguesa de Ciências Veterinárias, Lisboa: Sociedade Portuguesa de Ciências Veterinárias, v.101, n.557-558, p.121124. 2006.

[43]. HSIN-Y, C.; CHOU, C-C. Acid adaptation and temperature effect on the survival of $E$. coli 0157:H7 in acidic fruit juice and lactic fermented milk product. International Journal of Food Microbioly. v.70, n.1-2, p.189-195, out. 2001.
[44]. KASIMOGLU, A.; AKGÜN, S. Survival of Escherichia coli 0157:H7 in the processing and post-processing stages of acidophilus yogurt. International Journal of Food Science \& Technology. Wiley, v.39, n.5, p.563-568, mai. 2004.

[45]. MUFANDAEDZA, J.; VILJOEN, B.C.; FERESU, S.B.; GADAGA, T.H. Antimicrobial properties of lactic acid bacteria and yeast-LAB cultures isolated from traditional fermented milk against pathogenic Escherichia coli and Salmonella enteritidis strains. International Journal of Food Microbiology. Elsevier, v.108, n.1, p.147-152, abr. 2006. 